\title{
O MEIO AMBIENTE E A RESPONSABILIDADE CIVIL OBJETIVA POR DANOS AMBIENTAIS ${ }^{1}$
}

THE ENVIRONMENT AND OBJECTIVE CIVIL RESPONSIBILITY FOR ENVIRONMENTAL

DAMAGE

Clareana Isaac RODRIGUES ${ }^{2}$

Elizabete Cristiane de Oliveira Futami de NOVAES ${ }^{3}$

ISSUE DOI: 10.21207/2675-0104.2018.791

\begin{abstract}
RESUMO
O presente artigo visa investigar e confirmar a atuação predominante da responsabilidade civil objetiva nos julgados brasileiros referentes aos danos ambientais, bem como estudar o histórico do Direito Ambiental e identificar os regimentos legais ambientais vigentes no Brasil. Ademais, classificar os danos puníveis, as teorias utilizadas para estipular o nexo causal entre o dano e a atividade poluente, e pontuar a teoria mais eficaz. Conta, também, com o estudo comparativo, onde procura identificar as tendências mundiais sobre a responsabilização dos danos ambientais. A metodologia utilizada abrange levantamentos bibliográficos, documentais e comparativos de todos os materiais encontrados, capazes de analisar as diretrizes indagadas na pesquisa. Em suma, a problemática abordada dispõe sobre as soluções utilizadas no ordenamento jurídico brasileiro mais benéficas ao Meio Ambiente,
\end{abstract}

\footnotetext{
${ }^{1} \mathrm{O}$ presente artigo sintetiza a monografia de conclusão da pesquisa, realizada para o Programa Interno de Bolsas de Iniciação Científica (PIBIC 2017-2018) da Faculdade de Direito de Franca (FDF), Franca/SP.

${ }^{2}$ Discente da Faculdade de Direito de Franca (FDF), Franca/SP. Bolsista do Programa Interno de Bolsas de Iniciação Cientítica (PIBIC 2017-2018).

${ }^{3}$ Doutoranda em Ciências Jurídicas e Sociais pela UMSA Universidad del Museo Social Argentino, mestre em Direito pela Universidade de Franca e Especialista em Direito Processual Civil pela Universidade Estadual Paulista - UNESP. Atualmente exerce a função de professora do curso de Direito, ministrando a disciplina Direito Processual Civil; coordenadora do programa de Direitos Humanos e coordenadora do curso de pós-graduação da área de Direito Processual Civil: Atualização e Aplicação, no Centro Universitário do Planalto de Araxá-UNIARAXÁ e advogada militante.
} 
intencionando sempre a sua reparação in natura, para que este volte ao estado anterior ao da degradação, ou seja, retornar o meio ao seu status quo.

Palavras-chave: Direito Ambiental. Responsabilidade civil objetiva. Teoria do risco integral.

\section{ABSTRACT}

The present article aims to investigate and confirm the predominant role of the objective civil liability in the Brazilian judgements regarding environment damages, as well as to study the history of Environmental Law and identify the legal environmental regiments in force in Brazil. In addition, classify the punishable damages, the used theories to stipulate the causal nexus between the damage and the polluting activity, and punctuate the more effective theory. It also counts on the comparative study, where it seeks to identify the global trends in environmental liability. The methodology includes literature review, documents and comparatives of all the material found, which are able of analyzing the guidelines investigated in the research. In short, the problem addressed presents the most ecological solutions used in the Brazilian legal system, always intending to repair it in natura, so that it returns to his status quo.

Keywords: Environmental law. Objective civil liability. Theory of the integral risk.

\section{INTRODUÇÃO}

Por toda a história brasileira o Meio Ambiente foi negligenciado, sendo a priori tutelado de acordo com as convenções econômicas vigentes, do que sua prórpia proteção e reparação. Com a visível degradação do meio, houve uma mudança de perspectiva quanto à sua regulamentação, instaurando políticas públicas, como a responsabilidade civil para efetivar seu amparo.

O presente tema justifica-se e baseia-se no amparo jurisdicional quanto a responsabilização dos agentes poluidores, estabelecendo conceitos, classificações e comparações com o direito internacional para o ratificar. Sendo assim, o objetivo almejado é o de confirmar a adoção do sistema de responsabilidade civil objetiva, nos tribunais brasileiros, bem como identificar a melhor solução para a recuperação do meio e a teoria de nexo causal que condiz com a intenção do legislador.

$\mathrm{O}$ artigo se concentra fundamentalmente na pesquisa bibliográfica com consultas em doutrinas, jurisprudência, artigos científicos, sites jurídicos, entre outros materiais encontrados. Se valendo do método analítico, comparativo e, em determinados casos, até mesmo o método dialético. 


\section{A INTRÍNSECA RELAÇÃO DO AMBIENTE E DO DIREITO}

Sempre envolto em grande polêmica, o Meio Ambiente possui divergências quanto aos seus aspectos e conceituações. Sob a óptica antropológica, o meio passou a ser considerado a partir das relações humanas, por consequência insere o homem social e suas atividades.

Já o conceito legal do Meio Ambiente fica a cargo da Política Nacional do Meio Ambiente, estabelecida pela Lei Federal n. ${ }^{\circ}$ 6.938/81, nos art. $2 .^{\circ}$, I, c.c. art. $3 .^{\circ}$, I. Logo, o Meio Ambiente é considerado como "o conjunto de condições, leis, influências e interações de ordem física, química e biológica, que permite, abriga e rege a vida em todas as suas formas" (art. 3., I), sendo considerado "um patrimônio público a ser necessariamente assegurado e protegido, tendo em vista o uso coletivo" $\left(\operatorname{art.} 2 .^{\circ}, \mathrm{I}\right)^{4}$.

Para o Direito Ambiental, visa a sustentabilidade para as atuais e futuras gerações, regulando as atividades humanas que afetam ou possam afetar o equilíbrio do Meio Ambiente. Endossando a abordagem, Gina Copola, enfatiza a respeito da conceituação de Direito Ambiental ser o "conjunto de normas jurídicas, técnicas, regras e princípios tendentes a assegurar o equilíbrio ecológico, o desenvolvimento sustentável, e a sadia qualidade de vida de toda a coletividade, e de todo o ecossistema",

Justamente por ter seus respectivos princípios, legislação própria e objeto de proteção, o Direito Ambiental é um Direito autônomo, consequentemente a sua existência independe de outros ramos do direito ${ }^{6}$. Ademais, possui natureza de Direito Difuso, já que sua proteção transcende à do Direito Privado e Público, e atinge o interesse "pluriindividual"?

\section{DA LEGISLAÇÃO AMBIENTAL NO BRASIL}

Sendo a Constituição Federal o documento de maior importância dentro de um Estado democrático, uma de suas principais funções é

\footnotetext{
${ }^{4}$ LANFREDI, Geraldo Ferreira. Política ambiental: busca de efetividade de seus instrumentos. São Paulo: Revista dos Tribunais, 2002.

${ }^{5}$ COPOLA, Gina. Elementos de direito ambiental. Rio de Janeiro: Temas \& Ideias Editora, 2003, p. 29.

${ }^{6}$ Id., Ibid.

${ }^{7}$ MUKAI, Toshio. Direito ambiental sistematizado. 4. ed. Rio de Janeiro: Forense Universitária, 2002, p. 6.
} 
estabelecer os direitos e garantidas dos cidadãos contidos no Estado constituído $^{8}$. Consequentemente, é primordial estabelecer as garantias ambientais já estabelecida pelas Constituições anteriores e pela atual Carta Magna presente no país.

Com o advento da Carta Constitucional de 1988, o Meio Ambiente tornou-se um direito fundamental, garantido a todos, sendo estes não só as atuais, mas também as futuras gerações, vida digna, saúde e bemestar, proporcionados por um meio ambiente sadio 9 . Assim, por estar inserido entre os direitos fundamentais à vida do ser humano se classifica como uma cláusula pétrea, portanto, no rol dos direitos que são imutáveis aos olhos de uma possível reforma na Constituição ${ }^{10}$.

À vista do exposto, a Constituição de 1988 foi a primeira zelar pela completa tutela jurisdicional do Meio Ambiente, punindo todos as pessoas transgressores do meio equilibrado, prevendo sempre o desenvolvimento sustentável da economia nacional em respeito ao direito à sadia qualidade vida das gerações.

Além da tutela constitucional vale ressaltar a proteção infraconstitucional presente no direito nacional, merecendo destaque: as Leis de Política Nacional do Meio Ambiente, da Ação Civil Pública e a de Crimes Ambientais, como também o Código Florestal, que fora alterado pela Lei n. ${ }^{\circ} 12651$, de 25 de maio de 2012.

O Direito Ambiental como visto, é recente, mesmo que seu objeto de estudo esteja entre os seres humanos a milhares de anos. Seus estudos, desenvolvimento e proteção, passaram a ser tratados como prioridade a partir de 1980, ano em que esse Direito começou seu processo evolutivo, para deixar de ser antropocêntrico e se tornar biocêntrico.

\section{$4 \quad$ DOS DANOS AMBIENTAIS}

É dano ambiental, qualquer agressão a um ou mais elementos que compõem a concepção de meio ambiente dada pelo artigo $3 .^{\circ}$, inciso I, da

\footnotetext{
${ }^{8}$ LANÇA, João. O que é a Constituição e qual sua importância? Barroso \& França Advocacia, Minas Gerais, 21 mar. 2016. Disponível em: <https://www.barrosoefranca.com.br/single-post/2016/03/21/Oque-\%C3\%A9-a-Constitui\%C3\%A7\%C3\%A3o-e-qual-a-sua-import\%C3\%A2ncia>. Acesso em: 25 maio 2018.

${ }^{9}$ BALDRIGHI, Mariane. O meio ambiente como direito fundamental. Revista da Faculdade de Direito da Universidade de São Paulo, São Paulo, v. 93, p. 429-454, jan. 1998.

10 SARLET, Wolfgando Ingo; MACHADO Paulo Afonso Leme; FENSTERSEIFER, Tiago. Constituição e legislação ambiental comentadas. São Paulo: Saraiva, 2015.
} 
Lei n. ${ }^{\circ} 6.938 / 81$, causada por ato comissivo ou omissivo de qualquer pessoa $^{11}$.

A doutrina classifica a degradação ambiental em duas espécies, segundo a sua dimensão (dano ambiental coletivo e individual) e quanto a natureza do interessado (dano ambiental patrimonial e extrapatrimonial). Sendo que, um único dano ambiental pode importar, simultaneamente.

Em conformidade com a sua dimensão reconhece que não há danosidade apenas contra a natureza, mas também contra o ser humano, o qual é diretamente prejudicado com a degradação ambiental, confirmando, assim, a natureza dúplice em razão desta danosidade ${ }^{12}$. Esta natureza justifica-se com o artigo 14, $\S 1 .^{\circ}$, da Lei n..$^{\circ} 6938$, de 1981, onde afirma que em face aos danos causados, tanto o meio ambiente quanto terceiro afetado podem ser sujeitos passivos.

Em consequência, pode ser dividido esta espécie em dois tipos de danos: a) dano ambiental coletivo, são aqueles prejuízos causados diretamente ao meio ambiente, que prescinde de comprovação de lesão ao homem. Sua principal característica é a indivisibilidade, inerente ao meio ambiente devidamente equilibrado; e b) dano ambiental individual, também denominado dano ricochete ou dano reflexo, são aqueles sinistros que, alcançado o ecossistema de "forma imediata, repercutem de forma mediata na esfera individual de particulares (saúde, patrimônio ou bemestar) ou lesando o ente Público (bens públicos), singularmente considerados" $" 13$.

No tocante à natureza do interesse lesado, o critério de distinção do dano patrimonial e extrapatrimonial, faz-se perante os efeitos da lesão jurídica ao ofendido, ignorando, assim, a natureza do direito ou bem atingido ${ }^{14}$. Nada obsta, porém, de cumular as indenizações por estes danos, desde que provindos de um mesmo fato, como constata a Súmula 37 do STJ, "são cumuláveis as indenizações por dano material e dano moral oriundos do mesmo fato" 15 .

\footnotetext{
${ }^{11}$ SIRVINSKAS, Luís Paulo. Manual de direito ambiental. 13. ed. São Paulo: Saraiva, 2015.

${ }^{12}$ MILARÉ, Edis. Direito do ambiente. 9. ed. rev., atual., e ampl. São Paulo: Revista dos Tribunais, 2014.

${ }^{13}$ CARVALHO, D. W. Dano ambiental futuro: Da assimilação dos riscos ecológicos pelo direito à formação de vínculos jurídicos intergeracionais. 2006. 255 f. Tese (Doutorado em Ciências Jurídicas) - Programa de Pós-Graduação em Direito, Universidade do Vale do Rio dos Sinos, 2006, p. 160.

${ }^{14}$ DINIZ, Maria Helena. Curso de direito civil brasileiro: responsabilidade civil. 29. ed. São Paulo: Saraiva, 2015. v. 7.

${ }^{15}$ BRASIL. Superior Tribunal de Justiça. Súmula n. ${ }^{\circ} 37$. In: Súmulas. Julgado em 12 mar 1992,

Publicado em DJ 17 mar 1992.
} 
A Constituição Federal, em seu artigo $225, \S 3 .^{\circ}$, e a Lei de Política Nacional do Meio Ambiente (Lei n. ${ }^{\circ}$ 6938/1981), no art. 4. ${ }^{\circ}$, VII, dão respaldo a reparação e/ou indenização do dano ambiental, imputados aos seus causadores. O ordenamento jurídico brasileiro estabelece duas formas de recuperação, a recuperação in natura ou in specie e a compensação do dano por meio de indenização econômica, sendo que estas visam reparar a agressão sofrida pela natureza, afastar a ocorrência de atos semelhantes e recompensar a supressão de um meio harmonioso à sociedade $^{16}$. Ambas as formas de reparação podem ser impostas individual ou cumulativamente, devendo sempre, ter extrema cautela quanto sua aplicação, para que não haja o enriquecimento ilícito de nenhuma das partes.

Nesse passo, diz-se que a recuperação in specie é a recomposição de toda área afetada, ou seja, repristinação ao status quo ante, e a cessação imediata de todo e qualquer ato danoso ${ }^{17}$. Apesar de ser a forma ideal de recuperação, há dificuldades em reestabelecer, de modo idêntico, todos as substâncias e elementos biológicos do ambiente, mas sim, da maneira mais semelhante possível.

Sendo impossível a reparação natural ou demonstrando-se insatisfatória, deverá recorrer à indenização pecuniária, forma subsidiária de sanar o dano. Esta modalidade é complexa e há extrema dificuldades quanto a estipulação do quantum indenizatório, devendo este sempre se aproximar ao máximo do mal ocasionado à natureza e a terceiros prejudicados.

Entende-se, portanto, que a restauração in natura, é considerada a principal modalidade de recuperação ambiental, pois além de ser a melhor e mais benéfica à natureza, é também a primeira que deve ser tentada por todos, ainda que não haja certeza sobre seu êxito.

\section{$5 \quad$ RESPONSABILIDADE CIVIL DOS DANOS AMBIENTAIS}

Dentro do Direito Ecológico, a responsabilidade civil a ser adotada é consagrado pela Lei de Política Nacional do Meio Ambiente (Lei

\footnotetext{
${ }^{16}$ SAMPAIO, Francisco José Marques. Responsabilidade civil e reparação ao meio ambiente. 2. ed. Rio de Janeiro: Lumen Juris, 1998.

${ }^{17}$ SENDIM, José de Souza Cunhal. Responsabilidade civil por danos ecológicos: da reparação do dano através da restauração natural. Coimbra: Coimbra, 1998.
} 
n. $\left.{ }^{\circ} 6.938 / 81\right)^{18}$, a qual dispõe no art. $14, \S 1 .^{\circ}$, do diploma, que “[...] o poluidor obrigado, independentemente da existência de culpa, a indenizar ou reparar os danos causados ao meio ambiente e a terceiros, afetados por sua atividade". Adotando-se, portanto, o sistema da responsabilidade civil objetiva, no qual, a responsabilização é provada somente pelo dano, pela ação ou omissão do poluidor e pelo nexo de causalidade entre os dois ${ }^{19}$.

A ação ou omissão do agente não precisa ser ilícita para gerar a responsabilidade civil, diferentemente da responsabilidade administrativa e penal, onde é requisito fundamental. Atos lícitos, portanto, são sim passíveis de responsabilização.

Diante disso, a responsabilidade civil objetiva nos danos ambientais, é caracterizada pela solidariedade passiva dos contaminadores, eliminação das excludentes de responsabilidade e a adoção da teoria do risco integral, focando, principalmente, na prevenção e restauração do dano atual ou futuro ${ }^{20}$ e na potencialidade de risco da atividade para as gerações futuras, que também merecem ter seus interesses assegurados ${ }^{21}$.

O legislador adotou o princípio da solidariedade passiva para os autores de danos ambientais, com a pretensão de facilitar a restituição integral do meio. Tal medida fica evidenciado pela análise do artigo 942, caput, segunda parte, do Código Civil de 2002, onde estabelece que "se a ofensa tiver mais de um autor, todos responderão solidariamente pela reparação"22. E, pelo artigo 3..$^{\circ}$, inciso IV, da Lei n. ${ }^{\circ}$ 6.938/81, o qual determina que tanto os responsáveis diretos, como os indiretos pelos eventos danosos devem indenizar.

A aplicação da solidariedade passiva enseja o litisconsórcio facultativo, em regra, e o litisconsórcio necessário, por exceção, cabendo ao autor estabelecer quem deve ocupar o polo passivo da lide, desde que

\footnotetext{
${ }^{18}$ BRASIL. Lei n. 6938 de 31 de ago. 1981. Dispõe sobre a Política Nacional do Meio Ambiente, seus fins e mecanismos de formulação e aplicação, e dá outras providências. Diário Oficial da República Federativa do Brasil, Brasília, DF, 2 set. 1981. Disponível em: <http://www.planalto.gov.br/ccivil_03/leis/16938.htm>. Acesso em: 31 jul. 2017.

${ }^{19}$ GONÇALVES, Carlos Roberto. Direito civil brasileiro: responsabilidade civil. 9. ed. São Paulo: Saraiva, 2014. v. 4.

${ }^{20}$ COLOMBO, Silvana Raquel Brendler. O Princípio do poluidor-pagador. Âmbito Jurídico, Rio Grande, IX, n. 28, abr 2006. Disponível em: <http://www.ambitojuridico.com.br/site/index.php?n_link=revista_artigos_leitura\&artigo_id=932>. Acesso em: 4 jun. 2017.

${ }^{21}$ BARROSO, Lucas Abreu. Novas fronteiras da obrigação de indenizar. In: DELGADO, Mário Luiz; ALVES, Jones Figueiredo (Coord.). Questões controvertidas no novo Código Civil. São Paulo: Método, 2006. v. 5. p. 365.

${ }^{22}$ BRASIL. Lei n. 10.406, de 10 de jan. de 2002. Institui o Código Civil. Diário Oficial da República Federativa do Brasil, Brasília, DF, 11 de jan. de 2002. Disponível em: 〈https://www.planalto.gov.br/ccivil_03/leis/2002/110406.htm>. Acesso em: 02 ago. 2017.
} 
preenchido todos os requisitos legais da ação. Destarte, o autor pode ingressar com uma demanda contra qualquer um dos causadores do distúrbio ecológico, ou contra todos, ficando ao seu critério e oportunidade ${ }^{23}$.

O ordenamento jurídico brasileiro adotou a responsabilidade civil objetiva nos casos de danos ecológicos, afastando, assim, o elemento subjetivo da culpa de sua classificação, permanecendo somente três elementos principais, são eles a conduta, o dano e o nexo de causalidade entre esses ${ }^{24}$.

O nexo causal dentro da responsabilidade civil dos danos ambientais denota grande complexidade, em vista que estes danos "[...] são, frequentemente, produtos de várias causas concorrentes, simultâneas ou sucessivas, não se apresentando linearmente [...]"25. Por conseguinte, há diversas teorias criadas acerca do nexo causal entre o dano ecológico e a conduta do agente. Dentre elas, as que merecem destaque são as teorias da equivalência das condições (ou conditio sine qua non) e da causalidade adequada.

$\mathrm{Na}$ teoria da equivalência das condições, toda circunstância ou condição que tenha concorrido para o resultado é uma causa do delito e, se são mais de uma causa ou condição, todas possuem o mesmo valor, não diferenciando as principais das secundárias. Essa teoria é a adotada pelo Código Penal, conforme consta o artigo $13^{26}$.

Por sua vez, a teoria da causalidade adequada é aquela em que se deve analisar as causas anteriores ao fato e verificar qual foi a suficiente para acarretar o dano ${ }^{27}$. Portanto, nesta teoria, nem todas as circunstâncias são causas, somente as adequadas.

Nesta última, sustenta a teoria do risco criado, que por si só não é suficiente para o combate à impunidade daqueles que causam prejuízos ao meio ambiente, pois esta teoria rompe com o nexo causal em face das excludentes de responsabilidade civil, ou seja, com algum ato de força maior, fatos de terceiros e culpa exclusiva da vítima ${ }^{28}$. Consequentemente, se ocorrer um sinistro ao equilíbrio do meio, derivado de alguma atividade

\footnotetext{
${ }^{23}$ MILARÉ, Edis. Op. Cit. nota 11.

${ }^{24}$ CARVALHO, D. W. Op. Cit. nota 12.

${ }^{25}$ Id., Ibid., p. 189.

${ }^{26}$ AMADO, Frederico A. Di Trindade. Direito ambiental esquematizado. 3. ed. Rio de Janeiro: Forense, 2012.

${ }^{27}$ RODRIGUES, Marcelo Abelha. Direito ambiental esquematizado. São Paulo: Saraiva, 2013.

${ }^{28}$ MILARÉ, Edis. Op. Cit. nota 11.
} 
de risco, porém com alguma das excludentes, esse não imputará ao executor da atividade a responsabilidade pela danosidade causada.

A adoção da Teoria do Risco Integral funda-se em duas principais vertentes, a facilidade no ressarcimento dos danos provocados, e o fato do dano ambiental ser difuso, ou seja, atingir todos os seres da Terra, permitindo uma flexibilização do nexo para obter uma plena responsabilização de todos os atos danosos praticados ${ }^{29}$.

A facilidade alcançada no ressarcimento, advém não tão somente na dispensa da verificação da culpa do agente causador, mas também na possibilidade de haver responsabilidade sobre atividades lícitas ${ }^{30}$, pois estas mesmas que lícitas, se causarem dano e for comprovado o nexo causal, se estabelece a antijuridicidade do ato, já que a lei nacional coíbe à prática lesiva ao meio ambiente e impõe o dever de indenizar ${ }^{31}$.

Outra consequência é a não operabilidade das causas de excludentes de responsabilidade, portanto, mesmo que o fato danoso tenha ocorrido em face de caso fortuito, força maior, culpa exclusiva da vítima ou fato de terceiro, o responsável pela indústria é obrigado a sanar e indenizar os prejuízos alheios. Esta obrigação ocorre mesmo se a indústria em questão se valeu de todos os meios de precaução para evitar o dano, pois "pelo simples fato de existir a atividade há o dever de indenizar" 32 .

A jurisprudência, em harmonia com as doutrinas de Direito Civil e Ambiental também têm adotado a Teoria do Risco Integral. Nessa linha, o Superior Tribunal de Justiça pronunciou-se:

CIVIL. RECURSO ESPECIAL. RESPONSABILIDADE CIVIL. ROMPIMENTO DE BARRAGEM. "MAR DE LAMA" QUE INVADIU AS RESIDÊNCIAS. TEORIA DO RISCO INTEGRAL. NEXO DE CAUSALIDADE. SÚMULA N. 7/STJ. DANO MORAL IN RE IPSA. CERCEAMENTO DE DEFESA. VIOLAÇÃO AO ART. 397 DO CPC. INOCORRÊNCIA. 1. Inexiste violação do art. 535 do Código de Processo Civil se todas as questões jurídicas relevantes para a solução da controvérsia são apreciadas, de forma fundamentada, sobrevindo, porém, conclusão em sentido contrário ao almejado pela parte. 2. O fundamento do acórdão estadual de que a ré teve ciência dos documentos juntados em audiência, deixando, contudo, de impugná-los a tempo e modo e de manejar eventual agravo retido (sendo atingido, portanto, pela

\footnotetext{
${ }^{29}$ TARTUCE, Flávio. Direito Civil: Direito das obrigações e responsabilidade civil. 10. ed. rev., atual. e ampl. São Paulo: Método, 2015. v. 5.

${ }^{30}$ MILARÉ, Edis. Op. Cit. nota 11.

${ }^{31}$ MIRANDA, Francisco Cavalcanti Pontes de. Tratado de direito privado: T. LIII. São Paulo: RT, 2013. p. 143/144.

${ }^{32}$ NERY JÚNIOR, Nelson (Org.); ANDRADE NERY, Rosa Maria (Org.). Responsabilidade civil: direito ambiental. 1. ed. São Paulo: Editora Revista dos Tribunais, 2010. v. 7. p. 576.
} 
preclusão), bem como o fato de ter considerado os documentos totalmente dispensáveis para a solução da lide, não foi combatido no recurso especial, permanecendo incólume o aresto nesse ponto. Incidência da Súmula 283/STF. 3. É firme a jurisprudência do STJ no sentido de que, nos danos ambientais, incide a teoria do risco integral, advindo daí o caráter objetivo da responsabilidade, com expressa previsão constitucional (art. 225, $\$ 3^{\circ}$, da CF) e legal (art. 14, $\S 1^{\circ}$, da Lei $n$. 6.938/1981), sendo, por conseguinte, descabida a alegação de excludentes de responsabilidade, bastando, para tanto, a ocorrência de resultado prejudicial ao homem e ao ambiente advinda de uma ação ou omissão do responsável (STJ, REsp 1374342 MG, Quarta Turma, Relator: Ministro Luís Felipe Salomão, Julgamento: 10/09/2013, Publicação: DJe 25/09/2013, grifo nosso) ${ }^{33}$.

É importante salientar que embora a teoria do risco integral não esteja expressamente disposta no direito brasileiro, é a que mais se enquadra no estudo pormenorizado das legislações e jurisprudências, em relação à ampla proteção ambiental idealizada pelo legislativo.

\section{DIREITO COMPARADO: A RESPONSABILIZAÇÃO DO DANO NO MUNDO GLOBALIZADO}

Diferente do Brasil, a responsabilidade civil da degradação ambiental na Itália é, em sua maioria, subjetiva, ou seja, é preciso que na conduta do agente degradador fique constatado a culpa ou dolo ${ }^{34}$. Segundo Limardi (2011) citado por Karina Marcos Bedran e Elizabeth Mayes ${ }^{35}$, as exceções da responsabilidade subjetiva estão elencadas no anexo III da Diretiva 2004/35 CE, que enumera as atividades que vão ser responsabilizadas objetivamente pela justiça.

As diferenças entre o direito ambiental brasileiro e italiano são que o primeiro é solidário para com todos os poluidores, tem responsabilidade civil objetiva e possui uma vasta legislação sobre o

\footnotetext{
${ }^{33}$ BRASIL. Superior Tribunal de Justiça. Recurso Especial n. ${ }^{\circ} 1374342$ MG 2012/0179643-6. Quarta Turma. Recorrente: Mineração Rio Pomba Cataguases Ltda. Recorrido: Virgínia Antônia Nogueira e outros. Relator: Ministro Luís Felipe Salomão. Brasília, DF, 25 set. 2013. Disponível em: $<$ https://stj.jusbrasil.com.br/jurisprudencia/24226315/recurso-especial-resp-1374342-mg-20120179643-6-stj/inteiro-teor-24226316?ref=juris-tabs>. Acesso em: 10 out. 2017.

${ }^{34}$ BARACHO JÚNIOR, José Alfredo de Oliveira. Responsabilidade civil por dano ao meio ambiente. Belo Horizonte: Del Rey, 1999.

${ }^{35}$ BEDRAN, Karina Marcos; MAYER, Elizabeth. A responsabilidade civil por danos ambientais no direito brasileiro e comparado: teoria do risco criado vesus teoria do risco integral. Veredas do Direito, Belo Horizonte, v. 10, n. 19. jan./jun. 2013. p. 77.
} 
assunto; já na Itália, a responsabilidade também é solidária, mas apenas no limite da participação do agente no delito, a responsabilidade é subjetiva, com as exceções estipuladas no anexo III da Diretiva 2004/35 CE e sua proteção ambiental se faz com as Agências de Controle Ambiental, que detêm autonomia e se mostra bastante eficaz na prevenção de delitos ambientais.

Já nos Estados Unidos é o CERCLA, Comprehensive Environmental Response Compensation and Liability Act, modificado em 1986 pelo SARA, Superfund Amendments and Reauthorization Act, que legisla a responsabilidade civil por prejuízo ambiental causado por um agente poluidor ${ }^{36}$, bem como, determina as pessoas que podem ser responsabilizados.

Assim como no Brasil, é solidária a responsabilidade civil norteamericana, podendo ser culpabilizado o dono do local onde fora lançada as substâncias lesivas, o utilizador do local na época em que houve a poluição e qualquer outro participante no desenvolvimento da degradação ambiental $^{37}$. O sujeito responsável pelo dano deve arcar o prejuízo que causou a terceiros e também com toda a despesa que a EPA obteve ao impedir o dano de ocorrer, bem como a restauração do meio ambiente já degradado ${ }^{38}$.

Outra semelhança é a objetividade, afastando a culpa do agente passivo. Porém, diferente do Brasil, os EUA admitem três formas de exclusão da responsabilidade, que são: "1. o Act of God; 2. o Act of War; 3. o Act of Third Part" ${ }^{39}$. O Act of God é o equivalente aos eventos de caso fortuito ou força maior, ou seja, aqueles em que o ser humano é incapaz de controlar. Para o Act of War acontecer depende de um estado de guerra, que justifica e retira toda o dever de indenização de poluidor. E, por último, o Act of Third Part é o ato praticado por terceiro não relacionado com a empresa ou pessoa acusada de degradação ambiental.

$\mathrm{Na}$ América Latina, sendo o México o segundo país mais populoso, possui grande demanda de recursos naturais e, por conseguinte, eleva sua responsabilidade com o ambiente. Os dois maiores instrumentos de proteção ambiental mexicanos são, a Lei Geral do Equilíbrio Ecológico e Proteção Ambiental e a Lei Federal de Responsabilidade Ambiental, que foram promulgadas em, respectivamente, 1988 e 2013.

\footnotetext{
${ }^{36}$ Id., Ibid.

${ }^{37}$ LEMOS, Patrícia Faga Iglecias. Direito ambiental: responsabilidade civil e proteção ao meio ambiente. 2. ed. São Paulo: Revista dos Tribunais, 2008.

${ }^{38}$ BARACHO JÚNIOR, José Alfredo de Oliveira. Op. Cit. nota 33.

${ }^{39} I d$.
} 
A responsabilidade civil decorrente da degradação ambiental no México está disposta no segundo capítulo, Obligaciones Derivadas de los Daños Ocasionados al Ambiente, da Lei Federal de Responsabilidade Ambiental, mais especificamente nos arts. 11 e 12. Sendo que no primeiro artigo determina que a responsabilidade por danos ocasionados ao ambiente será subjetivo, e nascerá de ações ou omissões ilícitos, portanto aqueles que contrapõem as disposições legais, regulamentos e as normas oficiais do México. Também estabelece que há exceções a essa responsabilidade, que se encontram no mesmo título, no art. 12, onde estabelece que em qualquer ação ou omissão relacionadas com resíduos perigosos, com o uso ou operações de embarcações em recifes de coral, com a realização de atividades consideradas de alto risco e aquelas condutas previstas no art. 1913 do Código Civil Federal ${ }^{40}$.

Entretanto, tanto a responsabilidade subjetiva quanto a objetiva será exonerada nos casos de caso fortuito ou força maior, se a vítima consentiu a atividade danosa ao meio (não se aplica em casos de danos de interesse coletivos) e quando a causa do dano for estranha ao demandado ${ }^{41}$.

Isto posto, percebe-se um crescimento da tutela ambiente na maioria dos países, sendo que estes adotam a responsabilidade civil objetiva e solidária entre os poluentes para ampliar a eficácia da punição e inibir novas condutas lesivas ao meio. Até mesmo os países que ainda não adotam a responsabilidade civil como regra, tentam suprir com outros institutos de proteção ambiental, vide o México e suas políticas ambientais.

\section{CONSIDERAÇÕES FINAIS}

O Meio Ambiente é cercado de divergências doutrinarias e, em sua conceituação, não fora diferente, sendo que precisou-se de Lei Federal para estabelecer um conceito uno para o direito brasileiro, qual seja, a Lei n. ${ }^{\circ}$ 6.938/81, nomeada de Política Nacional do Meio Ambiente, no art. 3. ${ }^{\circ}$, I. Essa lei, bem como a Constituição Federal estabeleceu que o Direito Ambiental trata de Direito difuso e autônomo, ou seja, um direito atribuído

\footnotetext{
${ }^{40}$ MÉXICO. Presidencia de la republica. Ley Federal de Responsabilidad Ambiental. Nueva Ley publicada en el Diario Oficial de la Federación el 7 de Julio 2013. Disponível em: $<$ https://www.juridicas.unam.mx/legislacion/ordenamiento/ley-federal-de-responsabilidadambiental>. Acesso em 20 fev. 2018.

${ }^{41}$ TORRES, Jorge I. Aguilar. La responsabilidade civil objetiva por daños ambientales y su regulación en Mexico. Revista Electrónica de Derecho Ambiental, n. 18, jan. 2008. Disponível em: <http://huespedes.cica.es/gimadus/18/06.html>. Acesso em: 19 fev. 2018.
} 
a coletividade que independe de outros ramos do direito para sua existência.

Constata-se que, apesar de inúmeras as legislações ao longo da história nacional, as mais importantes são as Leis de Política Nacional do Meio Ambiente, da Ação Civil Pública e de Crimes Ambientais, que foram promulgadas, respectivamente, em 1981, 1985 e 1998. Também tem grande importância o Código Florestal, alterado em 2012. Na Constituição Federal, de 1988, o Direito Ambiental encontrou grande avanço, tendo as demais legislações, encontrado nela amparo constitucional.

O dano, seja ele degradação ou poluição ambiental, será considerado quando ultrapassar os limites impostos pelas leis ambientais, sendo que a ação do agente degradador não precisa ser ilícita, basta que cause algum sinistro que prejudique o meio ou terceiro.

No mais, após a ocorrência do dano, há duas formas de reparação, a in natura, que restabelece, no possível, a forma natural do meio, e a pecuniária, em que há uma indenização econômica pelos danos causados. A segunda é subsidiária quanto a primeira, como adota o entendimento jurisprudencial brasileiro.

Após identificado o dano e os agentes causadores, abre-se espaço para a responsabilização dos mesmos, que deve ser feita de forma objetiva, que independe de culpa do autor, amparado pela Lei n. ${ }^{\circ} 6938 / 81$, no art. $14, \S 1 .^{\circ}$ Sendo que para a efetiva comprovação do nexo causal entre a atividade e o dano, requisito essencial para configurar responsabilidade civil objetiva, é recomendável que se adote a Teoria do Risco Integral, que embora não esteja expressa no ordenamento jurídico brasileiro, é a que se enquadra quanto à ampla proteção ambiental visada pelas legislações atuais.

Por fim, as considerações sobre o direito comparado perante a responsabilização civil por danos ambientais, esclarecem que o direito brasileiro está avançado quanto alguns ordenamentos, porém sua falta de efetividade quanto à aplicação de suas leis ainda se encontra sem solução.

Os objetivos da pesquisa foram alcançados, haja vista que a matéria a respeito da responsabilidade civil objetiva foi abordada e finda a contextualização, não resta dúvida quanto a sua aplicação aos danos ambientais, bem como a teria adotada, a Teoria do Risco Integral. Teoria esta que está em crescente mundial, no que concerne ao nexo de causalidade, embora tenha encontrado maior respaldo no Direito Brasileiro, sedimentado no entendimento jurisprudêncial dos julgados de tribunais brasileiros. 


\section{REFERÊNCIAS BIBLIOGRÁFICAS}

AMADO, Frederico A. Di Trindade. Direito ambiental esquematizado. 3. ed. Rio de Janeiro: Forense, 2012.

BALDRIGHI, Mariane. O meio ambiente como direito fundamental. Revista da Faculdade de Direito da Universidade de São Paulo, São Paulo, v. 93, p. 429-454, jan. 1998.

BARACHO JÚNIOR, José Alfredo de Oliveira. Responsabilidade civil por dano ao meio ambiente. Belo Horizonte: Del Rey, 1999.

BARROSO, Lucas Abreu. Novas fronteiras da obrigação de indenizar. In: DELGADO, Mário Luiz; ALVES, Jones Figueiredo (Coord.). Questões controvertidas no novo Código Civil. São Paulo: Método, 2006. v. 5. p. 365.

BEDRAN, Karina Marcos; MAYER, Elizabeth. A responsabilidade civil por danos ambientais no direito brasileiro e comparado: teoria do risco criado vesus teoria do risco integral. Veredas do Direito, Belo Horizonte, v. 10, n. 19, p. 45-88. jan./jun. 2013.

BRASIL. Lei n. 10.406, de 10 de jan. de 2002. Institui o Código Civil. Diário Oficial da República Federativa do Brasil, Brasília, DF, 11 de jan. de 2002. Disponível em:

<https://www.planalto.gov.br/ccivil_03/leis/2002/110406.htm>. Acesso em: 02 ago. 2017.

. Lei n. 6938 de 31 de ago. 1981. Dispõe sobre a Política Nacional do Meio Ambiente, seus fins e mecanismos de formulação e aplicação, e dá outras providências. Diário Oficial da República Federativa do Brasil, Brasília, DF, 2 set. 1981. Disponível em: <http://www.planalto.gov.br/ccivil_03/leis/16938.htm>. Acesso em: 31 jul. 2017.

Superior Tribunal de Justiça. Recurso Especial n. ${ }^{\circ} 1374342$ MG 2012/0179643-6. Quarta Turma. Recorrente: Mineração Rio Pomba Cataguases Ltda. Recorrido: Virgínia Antônia Nogueira e outros. Relator: Ministro Luís Felipe Salomão. Brasília, DF, 25 set. 2013. Disponível em: <https://stj.jusbrasil.com.br/jurisprudencia/24226315/recurso-especial-resp-1374342-mg-20120179643-6-stj/inteiro-teor-24226316?ref=juris-tabs>. Acesso em: 10 out. 2017.

Superior Tribunal de Justiça. Súmula n. ${ }^{\circ} 37$. In: Súmulas. Julgado em 12 mar 1992, Publicado em DJ 17 mar 1992.

CARVALHO, D. W. Dano ambiental futuro: Da assimilação dos riscos ecológicos pelo direito à formação de vínculos jurídicos intergeracionais. 2006. 255 f. Tese (Doutorado em Ciências Jurídicas) - Programa de Pós-Graduação em Direito, Universidade do Vale do Rio dos Sinos, 2006.

COLOMBO, Silvana Raquel Brendler. O Princípio do poluidor-pagador. Âmbito Jurídico, Rio Grande, IX, n. 28, abr 2006. Disponível em:

<http://www.ambitojuridico.com.br/site/index.php?n_link=revista_artigos_leitura\&artigo_id=932>. Acesso em: 4 jun. 2017.

COPOLA, Gina. Elementos de direito ambiental. Rio de Janeiro: Temas \& Ideias Editora, 2003.

DINIZ, Maria Helena. Curso de direito civil brasileiro: responsabilidade civil. 29. ed. São Paulo: Saraiva, 2015. v. 7. 
GONÇALVES, Carlos Roberto. Direito civil brasileiro: responsabilidade civil. 9. ed. São Paulo: Saraiva, 2014. v. 4.

LANFREDI, Geraldo Ferreira. Política ambiental: busca de efetividade de seus instrumentos. São Paulo: Revista dos Tribunais, 2002.

LEMOS, Patrícia Faga Iglecias. Direito ambiental: responsabilidade civil e proteção ao meio ambiente. 2. ed. São Paulo: Revista dos Tribunais, 2008.

MEXICO. Presidencia de la republica. Ley Federal de Responsabilidad Ambiental. Nueva Ley publicada en el Diario Oficial de la Federación el 7 de Julio 2013. Disponível em:

$<$ https://www.juridicas.unam.mx/legislacion/ordenamiento/ley-federal-de-responsabilidadambiental>. Acesso em 20 fev. 2018.

MILARÉ, Edis. Direito do ambiente. 9. ed. rev., atual. e ampl. São Paulo: Revista dos Tribunais, 2014.

MIRANDA, Francisco Cavalcanti Pontes de. Tratado de direito privado: T. LIII. São Paulo: RT, 2013. p. $143 / 144$.

MUKAI, Toshio. Direito ambiental sistematizado. 4. ed. Rio de Janeiro: Forense Universitária, 2002, p. 6.

NERY JUNIOR, Nelson (Org.); ANDRADE NERY, Rosa Maria (Org.). Responsabilidade civil: direito ambiental. 1. ed. São Paulo: Editora Revista dos Tribunais, 2010. v. 7.

RODRIGUES, Marcelo Abelha. Direito ambiental esquematizado. São Paulo: Saraiva, 2013.

SAMPAIO, Francisco José Marques. Responsabilidade civil e reparação ao meio ambiente. 2. ed. Rio de Janeiro: Lumen Juris, 1998.

SARLET, Wolfgang Ingo; MACHADO, Paulo Afonso Leme; FENSTERSEIFER Tiago.

Constituição e legislação ambiental comentadas. São Paulo: Saraiva, 2015.

SENDIM, José de Souza Cunhal. Responsabilidade civil por danos ecológicos: da reparação do dano através da restauração natural. Coimbra: Coimbra, 1998.

SIRVINSKAS, Luís Paulo. Manual de direito ambiental. 13. ed. São Paulo: Saraiva, 2015.

TARTUCE, Flávio. Direito Civil: Direito das obrigações e responsabilidade civil. 10. ed. rev., atual. e ampl. São Paulo: Método, 2015. v. 5.

TORRES, Jorge I. Aguilar. La responsabilidade civil objetiva por daños ambientales y su regulación en Mexico. Revista Electrónica de Derecho Ambiental, n. 18, jan. 2008. Disponível em:

<http://huespedes.cica.es/gimadus/18/06.html〉. Acesso em: 19 fev. 2018. 